\title{
Heart Rate Variability in HIV Patients, Diabetics, and Controls: The AGATAA Study
}

\author{
Isabela M. Benseñor, ${ }^{1,2}$ Margareth Eira, ${ }^{3}$ Egídio Lima Dorea, ${ }^{2}$ Eduardo M. Dantas, ${ }^{4}$ \\ José Geraldo Mill, ${ }^{4}$ and Paulo A. Lotufo ${ }^{1,2}$ \\ ${ }^{1}$ School of Medicine, University of São Paulo, Sao Paulo, SP, Brazil \\ ${ }^{2}$ Hospital Universitario, University of São Paulo, Sao Paulo, SP, Brazil \\ ${ }^{3}$ Instituto de Infectologia Emílio Ribas, São Paulo, SP, Brazil \\ ${ }^{4}$ Federal University of Espírito Santo, Vitória, ES, Brazil \\ Correspondence should be addressed to Isabela M. Benseñor, isabensenor@hu.usp.br
}

Received 31 March 2011; Accepted 21 May 2011

Academic Editors: B. Hambly and P. Schoenhagen

Copyright ( $) 2011$ Isabela M. Benseñor et al. This is an open access article distributed under the Creative Commons Attribution License, which permits unrestricted use, distribution, and reproduction in any medium, provided the original work is properly cited.

HIV infection can affect cardiac autonomic function. We aimed to compare heart rate variability in 29 HIV-infected patients using highly active antiretroviral therapy (HAART), 28 naïve-treatment HIV patients, and diabetics with controls. There was no difference in time index parameters among groups. The normalized power of the low-frequency component (LF) in naïve patients of 39.9 (interquartile interval (IQ), 28.5-65.7) and diabetics of 42.9 (IQ, 14.5-57.7) were decreased compared with controls (67.5, IQ, 37.9-75.4). The normalized power of the high-frequency component (HF) in naïves of 49.7 (IQ, 30.4-64.8), and diabetics of 53.1 (IQ, 34.5-72.2) were increased compared with controls (27.0, IQ, 19.0-57.3). Naïve and diabetics also presented with lower LF/HF ratios (0.8 (IQ, 0.6-2.3), and 0.9 (IQ, 0.3-1.4), ) compared with controls (2.3 (IQ, 0.8-3.3)). We can speculate that HAART improves autonomic imbalance in frequency domain indices because there was no difference between the HAART group and controls.

\section{Introduction}

HIV infection can affect the heart, causing myocarditis, pericarditis, dilated cardiomyopathy, endocarditis, arrhythmias, coronary heart disease, and subclinical atherosclerosis [110]. Since the late 1980's and early 1990's, some studies have also identified changes related to the autonomic system leading to alterations in heart rate, postural hypotension, Valsalva maneuver, prolongation of the QT interval, deep breathing, response to isometric exercise, cold face test, urogenital problems, and mental stress [11-16]. Most of these autonomic alterations were identified in advanced, untreated cases [11-13]. Additionally some studies found a correlation between HIV infection and specific autonomic alterations in cardiac innervation and, consequently, cardiac function [15-26].

Recently, studies have evaluated heart rate variability in HIV-infected patients [17-19, 22, 24, 26], with most showing decreased heart rate variability similar to findings observed in patients with cardiomyopathy $[17,19,22,24]$. One study found increased heart rate variability [18], whereas another found no differences in baseline measures but observed a decrease in some heart rate variability parameters after the cold-face test and an increase after the tilt test [26]. Neild et al. evaluated and compared heart rate variability in HIVinfected patients and found variations in patients with cardiomyopathy compared with controls. Heart rate variability parameters were decreased in patients with cardiomyopathy and also to a high degree in HIV-infected patients compared with controls, suggesting an independent severe autonomic dysfunction not associated with heart disease [19].

Few studies evaluated the effect of treatment on heart rate variability in $\mathrm{HIV}$-infected patients. Correia et al. evaluated 40 patients using highly active antiviral therapy (HAART), 40 treatment-naïve HIV-infected patients (naïve), and 40 controls. The results showed no alterations in heart rate variability in HAART patients compared with naïve patients [26], suggesting that treatment prevents alterations 
in heart rate variability. Regarding the duration of disease, Becker et al. found severe autonomic nervous dysfunction in AIDS patients but not HIV-infected patients without AIDS [17]. Rogstad et al. evaluated AIDS patients, HIVinfected patients, and controls. The results showed evidence of substantial autonomic dysfunction in AIDS patients not using HAART compared with controls, but only mild abnormalities in HIV-infected patients [18], suggesting that the duration and severity of the disease but not the treatment were associated with autonomic dysfunction. All these data showed that there is a lot of conflicting results about the effect of treatment with HAART on the heart rate variability of HIV-infected patients and that more studies comparing HAART and naïve patients are still necessary.

The aim of this study was to compare alterations in heart rate variability in HIV-infected patients using HAART, naïve patients, and healthy controls. We also included a fourth group, diabetic patients, because diabetics have autonomic cardiac dysfunction and may be a reference for comparisons with HAART and naïve patients regarding severity of disease.

\section{Methods}

The "Avaliação Geral da Aterosclerose em Adultos" (AGATAA; Atherosclerosis Evaluation in Adults) study is a cross-sectional study designed to evaluate the presence of atherosclerosis in four groups; HIV-infected patients using highly active antiretroviral therapy (HAART), HIVinfected patients not using antiretroviral therapy (naïve), diabetic patients, and apparently healthy controls. All participants agreed to participate in the study and provided written informed consent. The study was approved by the Institutional Review Board.

2.1. Sample. The HAART and treatment-naïve patients were consecutively selected from a tertiary care outpatient clinic specializing in the treatment and followup of HIV-infected patients. Diabetic patients were consecutively selected from an outpatient clinic at the Hospital Universitário, a community and academic hospital affiliated to the University of São Paulo and located in the same area of the city of the tertiary care outpatient clinic specialized in treatment of HIV-infected patients. Control subjects were invited from a worksite periodic health examination from an affiliated institute of the same university. Controls were matched only to age (10-year) and sex with both HIV groups. Diabetes but not hypertension was an exclusion criteria for the control group; all patients agreed to submit to a protocol similar to the protocol applied to HIV-infected patients. Both groups had free access to medicines.

The mean time for diagnosis of HIV infection was different for HAART patients $(10.4 \pm 3.7$ years $)$ and for naïve patients $(6.5 \pm 4.8$ years $), P=0.001$. Patients using HAART presented a mean time of treatment of 7.7 (3.4) years. Mean nadir of CD4+ T-lymphocyte count was 207 (190) per $\mathrm{mm}^{3}$ for HAART group and 448 (176) for naïve subjects and the actual number of CD4+ is of 701 (400) for HAART and of 609 (307) for naïve patients. The median current viral load was of $3,741(10,312)$ for HAART and of $16,430(27,151)$ for naïve and most of HAART patients presents a viral load $<49$ copies $/ \mathrm{mL}$ compared to no one in the naïve group $(P<0.0001)$. No difference was found regarding CRP values among the groups. The mode of infection of these participants was as follow: heterosexual contact (40.3\%), homosexual (45.6\%), injecting drug users $(12.3 \%)$, and unknown (1.8\%).

2.2. Measurements. Anthropometric parameters were measured using standardized equipment and techniques according to the recommendations of World Health Organization and the Centers for Disease Control and Prevention (CDC) $[27,28]$. The following anthropometric measurements were recorded: weight, height, and waist and hip circumferences. All parameters were measured once except waist circumference, which was measured twice. Body mass index was obtained by dividing the weight in kilograms by the square of the height in meters [27]. Waist-to-hip ratio was obtained by dividing the waist circumference by the hip circumference [27].

Resting blood pressure and heart rate were measured three times in the seated position after a 5-minute rest. Measurements were obtained with an oscilometric sphygmomanometer (Omron 705CP) using an appropriate cuff on the nondominant arm. Blood pressure and heart rate were determined as the mean of two measurements.

2.3. Blood Samples. A blood sample was collected in the morning after a 12-hour fast to measure total cholesterol, LDL cholesterol, HDL cholesterol, and triglycerides. All participants, except confirmed diabetic patients, were given a glucose overload tolerance test (fasting glucose and after two hours of glucose overload).

2.4. Heart Rate Variability. Electrocardiography was performed using a digital electrocardiograph (Micromed, Brazil) at a sampling ratio of $250 \mathrm{~Hz}$. Wincardio (4.4a) software was used to automatically generate the R-R interval series from a selected EGG lead. Incorrect detections or ectopic beats were removed manually. ECG recordings were obtained from each participant while they were breathing spontaneously in a quiet room. The ECG record was obtained after five minutes of rest in a supine position.

Heart rate variability was assessed in time and frequency domains. Time domain analyses included mean RRi (ms), variance $\left(\mathrm{ms}^{2}\right)$, standard deviation of all $\mathrm{NN}$ intervals (SDNN), the proportion derived by a division of the number of pairs of adjacent $\mathrm{NN}$ intervals differing by more than $50 \mathrm{~ms}$ in the entire recording (NN50) by the total number of all $\mathrm{NN}$ intervals (pNN50), and, finally, the square root of the mean of sum of the squares of differences between adjacent NN intervals ( $r$-MSSD). Frequency domain analyses included low-frequency band (LF, $0.04-0.15 \mathrm{~Hz}$ ), highfrequency band (HF, $0.15-0.4 \mathrm{~Hz}$ ), and $\mathrm{LF} / \mathrm{HF}$ ratio, and were also presented as normalized values $[28,29]$. Power spectral analysis was performed with an autoregressive method and the model order was set at 16 [30]. Matlabcustomized software was used to determine temporal and spectral parameters of heart rate variability analyses. 
2.5. Clinical Evaluation. A patient was classified as hypertensive based on a self-reported medical diagnosis of high blood pressure, current treatment for hypertension, or a casual blood pressure $\geq 140 / 90 \mathrm{~mm} \mathrm{Hg}$ [31]. A patient was classified as diabetic based on a self-reported medical diagnosis of diabetes, current treatment for diabetes, or a positive tolerance test (after a glucose overload, a serum glucose level greater than $200 \mathrm{mg} / \mathrm{dL}$ measured after 120 minutes) [32]. A HIV-infected patient that also had a diagnosis of diabetes was classified as HAART or naïve. A patient was classified as dyslipidemic based on a self-reported medical diagnosis of hypercholesterolemia or hypertriglyceridemia, current treatment for hypercholesterolemia or hypertriglyceridemia, LDL-cholesterol $\geq 130 \mathrm{mg} / \mathrm{dL}$, HDL-cholesterol $\leq 40 \mathrm{mg} / \mathrm{dL}$, or triglycerides $\geq 150 \mathrm{mg} / \mathrm{dL}$ [33].

2.6. Statistical Analyses. Categorical variables were expressed as proportions. The chi-square test was used where appropriate. For continuous variables with normal distribution, we used analysis of variance (ANOVA) with post hoc Bonferroni test evaluation. Data on heart rate variability parameters were expressed as medians with interquartile intervals. Medians were compared using the Kruskal-Wallis nonparametric test and the Mann Whitney post hoc test for multiple comparisons. Mean values for high (HF) and low (LF) frequencies were also expressed as normalized values. Sample distribution or spread differences between the two groups were verified considering the indice values shown by the groups of participants that were below the 25th or above the 75th percentile observed in the control group to identify distinctive functional patterns among individuals in the four groups. For all tests, a two-tailed $P$ value less than $5 \%$ was considered significant. The analysis was done using SPSS (Statistical Package for Social Sciences) 16.0.

\section{Results}

The general characteristics of the subjects are shown in Table 1. The mean age of patients with diabetes was higher compared to the mean age of subjects in the other groups (for HAART, $P=0.009$; for naïve, $P<0.0001$; for controls, $P=0.001)$. Diabetics have presented a higher BMI compared to HAART $(P=0.01)$ and naïve $(P=0.04)$ patients and have also presented a higher waist measurement compared to the other groups (for HAART, $P=0.007$; for naïve, $P<0.0001$; for controls, $P=0.001)$. Regarding systolic blood pressure, only patients in the naïve group were different from diabetic patients $(P=0.03)$.

Table 2 shows the mean values of the RR intervals. There was no difference in the time index components according to the groups. However, the normalized low frequency component in the naïve and diabetic groups compared with controls $(P=0.03$ and $P=0.004$, resp.) and the normalized high frequency component, the median of the naïve and control groups, was higher compared with controls $(P=$ 0.02 and $P=0.005$, resp.). Naïve $(P=0.02)$ and diabetic patients $(P=0.004)$ had a lower LF/HF area compared with controls. There were five diabetics in the HAART group and one diabetic in the naïve group, but the results did not change when these patients were excluded from the analyses.

Table 3 shows the proportion of participants with HIV (both those receiving or not receiving treatment with HAART), and those with diabetes with time and frequency domain indices of heart rate variability, inside the limits or under or above the interquartile interval of the control group. For HIV-infected patients using HAART, most of the parameters analyzed for time domain indices are completely or at least partly below the control 25th percentile $(42.8 \%)$ compared with parameters completely or at least partly above the 25 th percentile of the control group (32.2\%), with $17.9 \%$ of HAART patients with more than one index simultaneously below the 25th percentile and above the control 75 th percentile of the control group. For naïve patients, $46.4 \%$ had parameters completely or partly above the 75 th percentile followed by $25 \%$ of parameters completely or partly below the 25 th percentile, and $17.9 \%$ with more than one index below the 25th percentile and above the 75th percentile of the control group. For diabetics, $16.7 \%$ of all indices are within the control interquartile range, followed by $33.4 \%$ of indices below the 25 th percentile, $26.1 \%$ above the 75 th percentile, and $23.8 \%$ both below the 25 th percentile and above the 75 th percentile.

Regarding frequency domain indices, the number of parameters within the control interquartile range was higher compared with time domain indices, with 39.3\% HIVinfected (HAART and treatment-naïve) patients and $38.1 \%$ of diabetics within the control interquartile range. However, most parameters were completely or partly below the 25th percentile or above the 75th percentile in $46 . \%, 42.8$, and $50 \%$ of HAART, naïve, and diabetic patients, respectively, (Table 4).

Further analysis comparing both genders did not show any differences among men and women (data not showed).

Our results suggest that previous evidence of impaired autonomic function associated with HIV infection in treatment-naïve patients could be similar to that found in diabetics. The normalized low-frequency component was decreased in HIV-infected, treatment-naïve patients, and diabetics compared with controls, whereas the highfrequency component was higher in treatment-naïve and diabetic patients compared with controls. Consequently, the $\mathrm{LH} / \mathrm{HF}$ ratio was different, with the treatment-naïve and diabetic patients having decreased ratios compared with controls. Based on these results, we can speculate that treatment with HAART improves the autonomic imbalance in frequency domain indices because there was no difference between the HAART group and the control group. No difference was found among the groups for time domain indices.

\section{Discussion}

Although autonomic dysfunction has been detected in AIDS patients since the 1980s, its effect on heart rate variability is not yet clearly defined. Most studies show a decreased autonomic cardiac function in AIDS patients for both time and frequency domain indices. However, patients included in 
TABLE 1: General characteristics and cardiovascular risk factors in the participants of the study including HIV people using or not treatment with HAART, diabetic, and controls.

\begin{tabular}{|c|c|c|c|c|c|}
\hline & HAART $N=29(\%)$ & Naïve $N=28$ & Diabetes $N=44(\%)$ & Controls $N=30(\%)$ & $P^{\mathrm{p}}$ \\
\hline Age $^{\mathrm{a}}$ (years) & $43.6(8.6)^{\mathrm{e}}$ & $42.0(6.7)^{\mathrm{f}}$ & $49.1(5.7)^{\mathrm{e}, \mathrm{f}, \mathrm{g}}$ & $42.4(7.9)^{\mathrm{g}}$ & $<0.0001$ \\
\hline Women $(\%)$ & $9(31)$ & $10(35.7)$ & $23(52.3)$ & $14(46.7)$ & 0.26 \\
\hline Body Mass Index $\left(\mathrm{kg} / \mathrm{m}^{2}\right)$ & $25.8(3.8)^{\mathrm{h}}$ & $26.2(4.9)^{\mathrm{i}}$ & $30.6(4.8)^{\mathrm{h}, \mathrm{i}}$ & $29.3(10.8)$ & 0.005 \\
\hline Rest Heart rate (beats/min) & $72.1(10.4)$ & $69.7(10.8)$ & $73.9(11.9)$ & $68.8(16.1)$ & 0.30 \\
\hline Waist circumference $(\mathrm{cm})$ & $90.4(10.8)^{j}$ & $86.9(11.4)^{\mathrm{k}}$ & $99.5(10.3)^{\mathrm{j}, \mathrm{k}, \mathrm{l}}$ & $89.2(13.9)^{\mathrm{g}}$ & $<0.0001$ \\
\hline Waist to hip ratio & $0.9(0.9)^{\mathrm{m}}$ & $0.9(0.8)$ & $0.9(0.7)^{\mathrm{n}}$ & $0.9(0.7)^{\mathrm{m}, \mathrm{n}}$ & $<0.0001$ \\
\hline Systolic blood pressure $(\mathrm{mm} \mathrm{Hg})^{\mathrm{a}}$ & $124.7(13.2)$ & $118.1(14.4)^{\mathrm{o}}$ & $127.8(12.4)^{\circ}$ & $119.7(15.7)$ & 0.01 \\
\hline Study years & & & & & 0.34 \\
\hline $0(\%)$ & $1(3.4)$ & $0(0)$ & $1(2.3)$ & $0(0)$ & \\
\hline $1-8$ years $(\%)$ & $4(10.7)$ & $7(25.0)$ & $4(9.4)$ & $6(20.0)$ & \\
\hline $9-11$ years $(\%)$ & $12(41.3)$ & $11(39.2)$ & $24(55.8)$ & $3(40.0)$ & \\
\hline$>11$ years $(\%)$ & $12(41.3)$ & $10(35.7)$ & $12(39.9)$ & $12(40.0)$ & \\
\hline Race & & & & & 0.65 \\
\hline White & $13(44.8)$ & $14(50.0)$ & $23(52.3)$ & $13(43.3)$ & \\
\hline Mixed & $10(34.5)$ & $12(42.9)$ & $14(31.8)$ & $14(46.7)$ & \\
\hline Black & $5(17.2)$ & $2(7.1)$ & $7(15.9)$ & $3(10.0)$ & \\
\hline Others & $1(3.4)$ & $0(0)$ & $0(0)$ & $0(90)$ & \\
\hline \multicolumn{6}{|l|}{ Smoking } \\
\hline Current (\%) & $7(38.9)$ & $6(42.9)$ & $9(30.0)$ & $5(33.3)$ & 0.84 \\
\hline High blood pressure $(\mathrm{mm} \mathrm{Hg})(\%)^{\mathrm{b}}$ & $12(41.4)$ & $8(28.6)$ & $36(81.8)$ & $8(26.7)$ & $<0.0001$ \\
\hline Diabetes $(\%)^{c}$ & $5(17.2)$ & $1(3.6)$ & $44(100)$ & $0(0)$ & $<0.0001$ \\
\hline Dislipidemia $(\%)^{\mathrm{d}}$ & $27(93.1)$ & $23(82.1)$ & $36(83.7)$ & $22(73.3)$ & 0.25 \\
\hline
\end{tabular}

HAART: highly active antiretroviral therapy.

${ }^{\mathrm{a}}$ Mean (standard deviation); ${ }^{\mathrm{b}}$ High blood pressure defined by self-report medical history of hypertension or current treatment for hypertension or systolic blood pressure $\geq 140 \mathrm{~mm} \mathrm{Hg}$ or diastolic blood pressure $\geq 90 \mathrm{~mm} \mathrm{Hg}$; ${ }^{\circ}$ Diabetes defined by self-report medical history of diabetes or current treatment for diabetes or a 120 minutes glucose test $\geq 200 \mathrm{mg} / \mathrm{dL}$; ${ }^{\mathrm{d}}$ Dislipidemia defined as self-reported medical history of dislipidemia or current treatment for dislipidemia or LDL-cholesterol $\geq 130 \mathrm{mg} / \mathrm{dL}$, HDL-cholesterol $\leq 40 \mathrm{mg} / \mathrm{dL}$ or triglycerides $\geq 150 \mathrm{mg} / \mathrm{dL}$.

${ }^{\mathrm{e}}$ Group HAART $\neq$ Group diabetes, $P<0.009$; ${ }^{\mathrm{f}}$ Group naïve $\neq$ Group diabetes, $P<0.0001$; ${ }^{\mathrm{g}}$ Group diabetes $\neq$ Group control, $P=0.001$; ${ }^{\mathrm{h}}$ Group HAART $\neq$ Group diabetes, $P=0.01$; ${ }^{\mathrm{i}}$ Group naïve $\neq$ Group diabetes, $P=0.04$; ${ }^{\mathrm{j}}$ Group HAART $\neq$ Group diabetes, $P<0.007$; ${ }^{\mathrm{k}}$ Group naïve $\neq$ Group diabetes, $P<0.0001 ;{ }^{1}$ Group diabetes $\neq$ Group control, $P=0.001 ;{ }^{\mathrm{m}}$ Group HAART $\neq$ Group control, $P=0.003$; ${ }^{\mathrm{n}}$ Group diabetes $\neq$ group control, $P<0.002$; ${ }^{\circ}$ group naïve $\neq$ group diabetes, $P<0.03$.

${ }^{\mathrm{p}} P$ values for differences among the four categories applying $F$-test for continuous variables and or Chi-square for categorical variables.

TABLE 2: Median (interquartile interval) of the time and frequency domain indices of heart rate variability in HIV-infected patients (treated or not treated with HAART), diabetics, and controls.

\begin{tabular}{|c|c|c|c|c|c|}
\hline & HAART $N=29(\%)$ & Naïve $N=28$ & Diabetes $N=44(\%)$ & Controls $N=30(\%)$ & $P$ \\
\hline \multicolumn{6}{|c|}{ Time Index } \\
\hline R-R Interval (m/s) & $903.1(758.9-959.5)$ & $908.1(771.1-1007.5)$ & $883.2(755.0-933.3)$ & $844.3(797.1-914.8)$ & 0.55 \\
\hline $\operatorname{SDNN}(\mathrm{m} / \mathrm{s})$ & $26.9(34.2-64.3)$ & $45.6(33.0-72.5)$ & $39.1(25.5-42.7)$ & $45.6(32.3-62.3)$ & 0.059 \\
\hline pNN50 (\%) & $3.1(0.6-11.0)$ & $5.4(1.0-28.5)$ & $3.4(0.9-12.0)$ & $7.7(1.6-20.4)$ & 0.32 \\
\hline r-MSSD (ms) & $26.2(18.5-48.8)$ & $36.5(25.4-69.2)$ & $25.8(17.8-40.3)$ & $30.7(219.2-43.7)$ & 0.36 \\
\hline Low frequency spectral area $\left(\mathrm{ms}^{2}\right)$ & $45.8(23.1-60.1)$ & $42.2(33.2-68.2)$ & $25.8(17.8-40.3)^{\mathrm{a}}$ & $60.3(40.3-73.3)^{\mathrm{a}}$ & 0.06 \\
\hline High frequency spectral area $\left(\mathrm{ms}^{2}\right)$ & $46.2(31.2-74.1)$ & $47.5(29.5-60.4)$ & $50.1(42.1-67.9)^{\mathrm{b}}$ & $29.5(21.8-58.2)^{\mathrm{b}}$ & 0.06 \\
\hline Normalized low frequency area & $46.1(30.6-62.0)$ & $39.9(28.5-65.7)^{\mathrm{c}}$ & $42.9(14.5-57.7)^{\mathrm{d}}$ & $67.5(37.9-75.4)^{\mathrm{c}, \mathrm{d}}$ & 0.04 \\
\hline Normalized high frequency area & $45.3(30.6-67.2)$ & $49.7(30.4-64.8)^{\mathrm{e}}$ & $53.5(34.5-72.2)^{\mathrm{f}}$ & $27.0(19.0-57.3)^{\mathrm{e}, \mathrm{f}}$ & 0.03 \\
\hline $\mathrm{LF} / \mathrm{HF}$ area & $1.1(0.3-1.7)$ & $0.8(0.6-2.3)^{\mathrm{g}}$ & $0.9(0.3-1.4)^{\mathrm{h}}$ & $2.3(0.8-3.3)^{\mathrm{g}, \mathrm{h}}$ & 0.04 \\
\hline
\end{tabular}

HAART: highly active antiretroviral therapy; SDNN: standard deviation of all NN intervals; pNN50: the proportion derived by a division of the number of pairs of adjacent NN intervals differing by more than $50 \mathrm{~ms}$ in the entire recording by the total number of all NN intervals; r-MSSD, the square root of the mean of sum of the squares of differences between adjacent NN intervals; LF: low frequency; HF: high frequency.

$P$ values for differences among the four categories applying $F$-test for continuous variables and or Chi-square for categorical variables.

* Median (interquartile interval).

${ }^{a}$ diabetics $\neq$ controls, $P=0.006$; ${ }^{b}$ diabetics $\neq$ controls, $P=0.01$; ${ }^{c}$ naïve $\neq$ controls, $P=0.05$; diabetics $\neq$ controls, $P=0.004$; ${ }^{\mathrm{e}}$ naïve $\neq$ controls, $P=0.03$; $^{\mathrm{f}}$ diabetics $\neq$ controls, $P=0.004$; $^{\mathrm{g}}$ naïve $\neq$ controls, $P=0.02$, $^{\mathrm{h}}$ diabetics $\neq$ controls, $P=0.005$. 
TABLE 3: Proportion of HIV-infected participants (treated or not treated with HAART) or diabetic patients with time and frequency domain indices of heart rate variability inside the limits or under or above the interquartile interval of the control group.

\begin{tabular}{lcccccc}
\hline & \multicolumn{2}{c}{ HAART $N=29$} & \multicolumn{2}{c}{ Naïve $N=28$} & \multicolumn{2}{c}{ Diabetics $N=44$} \\
& Time index & Frequency index & Time index & Frequency index & Time index & Frequency index \\
\hline $\begin{array}{l}\text { All index within the control } \\
\text { interquartile range, } n \text { (\%) }\end{array}$ & $2(7.1)$ & $11(39.3)$ & $3(10.7)$ & $11(39.3)$ & $7(16.7)$ & $16(38.1)$ \\
$\begin{array}{l}\text { All index below the control 25th } \\
\text { percentile, } n \text { (\%) }\end{array}$ & $4(14.3)$ & - & $2(7.1)$ & - & $7(16.7)$ & - \\
$\begin{array}{l}\text { One or more index exclusively below } \\
\text { the control 25th percentile, } n(\%)\end{array}$ & $8(28.5)$ & $3(10.7)$ & $5(17.9)$ & $5(17.9)$ & $7(16.7)$ & $5(11.9)$ \\
$\begin{array}{l}\text { All index above the control 75th } \\
\text { percentile, } n \text { (\%) }\end{array}$ & $4(14.3)$ & - & $4(14.3)$ & - & $1(2.3)$ & - \\
$\begin{array}{l}\text { One or more index exclusively above } \\
\text { the control 75th percentile, } n \text { (\%) }\end{array}$ & $5(17.9)$ & $1(3.6)$ & $9(32.1)$ & - & $10(23.8)$ & - \\
$\begin{array}{l}\text { More than one index simultaneously } \\
\text { below the control 25th percentile and } \\
\text { above the control 75th percentile, } n\end{array}$ & $5(17.9)$ & $13(46.4)$ & $5(17.9)$ & $12(42.8)$ & $10(23.8)$ & $21(50)$ \\
(\%) & & & & & \\
\hline
\end{tabular}

HAART: highly active antiretroviral therapy.

the studies and the autonomic tests used were heterogeneous making comparisons between studies difficult. However, most studies evaluated heart rate variability in the supine position, permitting some comparisons. In 1997, Becker et al. evaluated heart rate variability in HIV-infected and AIDS patients and controls. Median values of abnormal heart rate variability parameters $(<10$ th percentile of the controls) were found in $9.1 \%$ of AIDS patients, but no difference was found between HIV-infected patients and controls [17]. AIDS patients exhibited a decrease in fourteen heart rate variability parameters, including time and frequency domains (93.3\%), compared with healthy people, whereas HIV-infected patients (pre-AIDS) showed a trend towards decreases in five heart rate variability parameters $(33.3 \%)$ compared with healthy controls. Only seven $(20 \%)$ of the HIV-positive patients were receiving zidovudine [17].

Mittal et al. evaluated naïve patients and controls. All time and frequency domain indices were decreased in the naïve patients compared with controls [22]. Sakhuja et al. evaluated HIV-infected patients and controls regarding heart rate variability. Except for variance, no difference was found between HIV-infected patients and controls in the sample [24]. Correia et al. evaluated heart rate variability in a group of HAART patients, a group of HIV-infected, treatmentnaïve patients, and controls. Except for the normalized power of the low frequency (LF) component and the LF/HF ratio, which was significantly decreased in the naïve group compared with HAART patients and controls, no differences were found [26]. However, Rogstad et al. evaluated heart rate variability and other cardiovascular autonomic tests in HIVinfected inpatients and controls. Significant differences were found between AIDS patients and controls for supine heart rate variability, with AIDS patients having a higher heart rate, suggesting unopposed cardiac sympathetic activity $(P<$ $0.001)$ [18].

Our results did not show any differences in time domain indices among the groups. However, we found lower normalized LF component values in naïve and diabetic patients compared with controls, and higher normalized HF component values in naïve and diabetic patients compared with controls. As a consequence, the $\mathrm{LF} / \mathrm{HF}$ area in naïve and diabetic patients were lower compared with controls $(P=0.04)$, similar to the results found by Correia et al. for HIV-infected, treatment-naïve patients [26]. We did not find any differences between the HAART and naïve groups; however, in both studies, HAART patients showed an intermediary value for the LF/HF ratio that was between the naïve (the lowest value) and controls (the highest value), but the difference was not statistically significant.

Our study included an additional group of patients with diabetes. Cardiovascular autonomic neuropathy is frequently present in diabetic patients, and can cause abnormalities in heart rate control and alterations in central and peripheral vascular dynamics [34]. Some studies identified reduced time and frequency domain indices in heart rate variability in diabetic patients [35-40]. Our objective in including a diabetic group in the study was to compare the severity of autonomic dysfunction in HIV patients with diabetics with controls. Diabetes is a disorder that effectively compromises cardiovascular autonomic function, and can be used as a reference for autonomic imbalance. Our results for naïve patients were very similar to the results for diabetics regarding normalized low and high frequency areas and the LF/HF area, which was in contrast with the HAART group, which never had values that were statistically different from the control group.

In general, we did not find large differences in heart rate variability among the groups. One possibility is that our measures were restricted to heart rate variability in a supine position. Several other tests can evaluate cardiovascular autonomic neuropathy such as the cold-face test, tilt test, or measurement of heart rate variability under different conditions like the Valsalva maneuver or deep inspiration. 
TABle 4: Proportion of participants with HIV using or not HAART or using diabetes with time and frequency domain indices of heart rate variability inside the limits or under or above the interquartile interval of the control group in men and women.

\begin{tabular}{|c|c|c|c|c|}
\hline & \multicolumn{4}{|c|}{ HAART } \\
\hline & \multicolumn{2}{|c|}{$\operatorname{Men}(N=19)$} & \multicolumn{2}{|c|}{ Women $(N=9)$} \\
\hline & Time index & Frequency index & Time index & Frequency index \\
\hline $\begin{array}{l}\text { All index within the control interquartile } \\
\text { range }\end{array}$ & $1(5.3)$ & $4(21.1)$ & $2(22.2)$ & $4(44.4)$ \\
\hline All index below the control 25th percentile & $2(10.5)$ & $0(0)$ & $2(22.2)$ & $0(0)$ \\
\hline $\begin{array}{l}\text { One or more index exclusively below the } \\
\text { control 25th percentile }\end{array}$ & $7(36.8)$ & $0(0)$ & $1(11.1)$ & $1(11.2)$ \\
\hline All index above the control 75th percentile & $2(10.5)$ & $0(0)$ & $1(11.1)$ & $0(0)$ \\
\hline $\begin{array}{l}\text { One or more index exclusively above the } \\
\text { control 75th percentile }\end{array}$ & $3(15.8)$ & $0(0)$ & $3(33.4)$ & $0(0)$ \\
\hline $\begin{array}{l}\text { More than one index simultaneously below } \\
\text { the control } 25 \text { th percentile and above the } \\
\text { control } 75 \text { th percentile }\end{array}$ & $4(21.1)$ & $15(78.9)$ & $0(0)$ & $4(44.4)$ \\
\hline \multirow[t]{4}{*}{ Total } & $19(100 \%)$ & $19(100 \%)$ & $9(100 \%)$ & $9(100 \%)$ \\
\hline & \multicolumn{4}{|c|}{ Naïve } \\
\hline & \multicolumn{2}{|c|}{$\operatorname{Men}(N=18)$} & \multicolumn{2}{|c|}{ Women $(N=10)$} \\
\hline & Time index & Frequency index & Time index & Frequency index \\
\hline $\begin{array}{l}\text { All index within the control interquartile } \\
\text { range }\end{array}$ & $2(11.1)$ & $6(33.3)$ & $1(10.0)$ & $7(70.0)$ \\
\hline All index below the control 25th percentile & $2(11.1)$ & $0(0)$ & $1(10.0)$ & $0(0)$ \\
\hline $\begin{array}{l}\text { One or more index exclusively below the } \\
\text { control 25th percentile }\end{array}$ & $7(38.9)$ & $1(5.6)$ & $1(10.0)$ & $1(10.0)$ \\
\hline All index above the control 75th percentile & $4(22.2)$ & $0(0)$ & $0(0)$ & $0(0)$ \\
\hline $\begin{array}{l}\text { One or more index exclusively above the } \\
\text { control 75th percentile }\end{array}$ & $1(5.6)$ & $1(5.6)$ & $6(60.0)$ & $0(0)$ \\
\hline $\begin{array}{l}\text { More than one index simultaneously below } \\
\text { the control } 25 \text { th percentile and above the } \\
\text { control } 75 \text { th percentile }\end{array}$ & $2(11.1)$ & $10(55.5)$ & $1(10.0)$ & $2(20.0)$ \\
\hline \multirow[t]{4}{*}{ Total } & $18(100 \%)$ & $18(100 \%)$ & $10(100 \%)$ & $10(100 \%)$ \\
\hline & \multicolumn{4}{|c|}{ Diabetes } \\
\hline & \multicolumn{2}{|c|}{$\operatorname{Men}(N=21)$} & \multicolumn{2}{|c|}{ Women $(N=23)$} \\
\hline & Time index & Frequency index & Time index & Frequency index \\
\hline $\begin{array}{l}\text { All index within the control interquartile } \\
\text { range }\end{array}$ & $1(4.8)$ & $4(19.1)$ & $4(18.2)$ & $12(54.5)$ \\
\hline All index below the control 25th percentile & $5(23.8)$ & & $1(4.5)$ & $1(4.6)$ \\
\hline $\begin{array}{l}\text { One or more index exclusively below the } \\
\text { control 25th percentile }\end{array}$ & $7(33.3)$ & $1(4.8)$ & $6(27.2)$ & - \\
\hline All index above the control 75th percentile & - & - & $1(4.8)$ & - \\
\hline $\begin{array}{l}\text { One or more index exclusively above the } \\
\text { control 75th percentile }\end{array}$ & $3(14.3)$ & & $8(36.3)$ & $1(4.6)$ \\
\hline $\begin{array}{l}\text { More than one index simultaneously below } \\
\text { the control } 25 \text { th percentile and above the } \\
\text { control 75th percentile }\end{array}$ & $5(23.8)$ & $16(76.0)$ & $2(9.0)$ & $8(36.3)$ \\
\hline Total & $21(100 \%)$ & $21(100 \%)$ & $22(100 \%)$ & $22(100 \%)$ \\
\hline
\end{tabular}

Although the sample size was not very large, it is also possible that because we included other tests and had an increased number of patients in each group compared to previous reports, we were able to find more differences among them. However, our results are very similar to those of Correia et al. regarding the HAART and naïve groups compared with controls, suggesting that treatment for HIV-infection may improve the autonomic alterations [26]. Both our and the Correia et al. studies were performed in Brazil; hence, it is possible that some characteristics of heart rate variability in $\mathrm{HIV}$-infected patients are related to aspects of HIV-infection in Brazilian patients. 
A possible common pathway for cardiovascular autonomic neuropathy in HIV infection and diabetes is systemic inflammation. Lampert et al. studied 264 middle-aged male twins free of symptomatic coronary heart disease with 24hour heart rate variability measurement correlating with inflammatory markers that are traditional cardiovascular risk factors, including ultrasensitive C-reactive protein (CRP) and interleukin 6. The results showed an association between CRP and decreased variability, even after controlling for traditional cardiovascular risk factors [41]. In our study, we did not find any association between CRP levels and HRV parameters.

Our study has some limitations because we only evaluated short-term heart rate variability in the supine position in a small sample. However, it is one of the first analyses that included HAART, HIV-infected, treatment-naïve, and diabetic patient groups and compared them with a group of controls.

\section{Conclusion}

Our results suggest that cardiovascular autonomic neuropathy in naive and diabetic patients is similar, with a decrease in normalized LF, increase in normalized HF, and a decrease in the LF/HF ratio compared with the control group. Our results could also suggest that treatment for HIV infection is possibly effective in improving autonomic dysfunction.

\section{Abbreviations}

HIV: $\quad$ Human Deficiency Virus

HAART: Highly Active Antiretroviral Therapy

LF: Low-frequency component

HF: High-frequency component.

\section{Author's Contributions}

Dr. I. M. Benseñor participated in the data collection and analysis, statistics, interpretation of data and drafting and critical revision of paper: Dr. M. Eira participated in the design, data analysis, interpretation and drafting of the paper; Dr. E. L. Dorea participated in the design, data analysis, interpretation and drafting of the paper; Dr. E. M. Dantas participated in the data collection and analysis/interpretation, drafting paper, and critical revision of paper; Dr. J. G. Mill participated in the data collection and analysis/interpretation, drafting article and critical revision of paper; Dr. P. A. Lotufo participated in the funding, concept/design, data analysis, interpretation of data, drafting and critical revision of the paper.

\section{Acknowledgments}

This project was funded by Fundação de Amparo a Pesquisa do Estado de São Paulo, São Paulo, Brazil. Drs. I. M. Benseñor, J. G. Mill and P. A. Lotufo are recipients are recipients of a scholarship from Conselho Nacional de Pesquisa, CNPq, Brasília, Brazil.

\section{References}

[1] P. F. Currie, A. J. Jacob, A. R. Foreman, R. A. Elton, R. P. Brettle, and N. A. Boon, "Heart muscle disease related to HIV infection: prognostic implications," British Medical Journal, vol. 309, no. 6969, pp. 1605-1607, 1994.

[2] G. Barbaro, "HIV-Associated Myocarditis," Heart Failure Clinics, vol. 1, no. 3, pp. 439-448, 2005.

[3] B. M. Mayosi, C. S. Wiysonge, M. Ntsekhe et al., "Clinical characteristics and initial management of patients with tuberculous pericarditis in the HIV era: the Investigation of the Management of Pericarditis in Africa (IMPI Africa) registry," BMC Infectious Diseases, vol. 6, article 2, 2006.

[4] G. Barbaro and S. E. Lipshultz, "Pathogenesis of HIVassociated cardiomyopathy," Annals of the New York Academy of Sciences, vol. 946, pp. 57-81, 2001.

[5] K. A. Gebo, M. D. Burkey, G. M. Lucas, R. D. Moore, and L. E. Wilson, "Incidence of, risk factors for, clinical presentation, and 1-year outcomes of infective endocarditis in an urban HIV cohort," Journal of Acquired Immune Deficiency Syndromes, vol. 43, no. 4, pp. 426-432, 2006.

[6] N. Reinsch, C. Buhr, P. Krings et al., "Prevalence and risk factors of prolonged QTc interval in HIV-infected patients: results of the HIV-HEART study," HIV Clinical Trials, vol. 10, no. 4, pp. 261-268, 2009.

[7] M. U. Sani and B. N. Okeahialam, "QTc interval prolongation in patients with HIV and AIDS," Journal of the National Medical Association, vol. 97, no. 12, pp. 1657-1661, 2005.

[8] N. J. Mehta, I. A. Khan, R. N. Mehta, and R. M. Gowda, "Acute coronary syndrome in patients with human immunodeficiency virus disease," Angiology, vol. 53, no. 5, pp. 545-549, 2002.

[9] L. A. Kingsley, J. Cuervo-Rojas, A. Muñoz et al., "Subclinical coronary atherosclerosis, HIV infection and antiretroviral therapy: multicenter AIDS Cohort Study," AIDS, vol. 22, no. 13, pp. 1589-1599, 2008.

[10] R. G. Micheletti, G. A. Fishbein, M. C. Fishbein et al., "Coronary atherosclerotic lesions in human immunodeficiency virus-infected patients: a histopathologic study," Cardiovascular Pathology, vol. 18, no. 1, pp. 28-36, 2009.

[11] J. A. Cohen and M. Laudenslager, "Autonomic nervous system in involvement in patients with human immunodeficiency virus infection," Neurology, vol. 39, no. 8, pp. 1111-1112, 1989.

[12] R. Freeman, M. S. Roberts, L. S. Friedman, and C. Broadbridge, "Autonomic function and human immunodeficiency virus infection," Neurology, vol. 40, no. 4, pp. 575-580, 1990.

[13] S. Ruttimann, P. Hilti, G. A. Spinas, and U. C. Dubach, "High frequency of human immunodeficiency virus-associated autonomic neuropathy and more severe involvement in advanced stages of human immunodeficiency virus disease," Archives of Internal Medicine, vol. 151, no. 12, pp. 2441-2443, 1991.

[14] S. B. Welby, S. J. Rogerson, and N. J. Beeching, "Autonomic neuropathy is common in human immunodeficiency virus infection," Journal of Infection, vol. 23, no. 2, pp. 123-128, 1991.

[15] A. Villa, V. Foresti, and F. Confalonieri, "Autonomic neuropathy and prolongation of QT interval in human immunodeficiency virus infection," Clinical Autonomic Research, vol. 5, no. 1, pp. 48-52, 1995.

[16] G. Scott, A. Piaggesi, and D. J. Ewing, "Sequential autonomic function tests in HIV infection," AIDS, vol. 4, no. 12, pp. 12791281, 1990.

[17] K. Becker, I. Görlach, T. Frieling, and D. Häussinger, "Characterization and natural course of cardiac autonomic nervous 
dysfunction in HIV-infected patients," AIDS, vol. 11, no. 6, pp. 751-757, 1997.

[18] K. E. Rogstad, R. Shah, G. Tesfaladet, M. Abdullah, and I. Ahmed-Jushuf, "Cardiovascular autonomic neuropathy in HIV infected patients," Sexually Transmitted Infections, vol. 75, no. 4, pp. 264-267, 1999.

[19] P. J. Neild, A. Amadi, P. Ponikowski, A. J. Coats, and B. G. Gazzard, "Cardiac autonomic dysfunction in AIDS is not secondary to heart failure," International Journal of Cardiology, vol. 74, no. 2-3, pp. 133-137, 2000.

[20] K. A. Brownley, J. R. Milanovich, S. J. Motivala et al., "Autonomic and cardiovascular function in HIV spectrum disease: early indications of cardiac pathophysiology," Clinical Autonomic Research, vol. 11, no. 5, pp. 319-326, 2001.

[21] D. Nzuobontane, B. K. Ngu, and K. Christopher, "Cardiovascular autonomic dysfunction in Africans infected with human immunodeficiency virus," Journal of the Royal Society of Medicine, vol. 95, no. 9, pp. 445-447, 2002.

[22] C. M. Mittal, N. Wig, S. Mishra, and K. K. Deepak, "Heart rate variability in human immunodeficiency virus-positive individuals," International Journal of Cardiology, vol. 94, no. 1, pp. 1-6, 2004.

[23] D. C. Chow, R. Wood, A. Grandinetti, C. Shikuma, I. Schatz, and P. Low, "Cardiovagal autonomic dysfunction in relation to HIV-associated lipodystrophy," HIV Clinical Trials, vol. 7, no. 1, pp. 16-23, 2006.

[24] A. Sakhuja, A. Goyal, A. K. Jaryal et al., "Heart rate variability and autonomic function tests in HIV positive individuals in India," Clinical Autonomic Research, vol. 17, no. 3, pp. 193 196, 2007.

[25] C. Compostella, L. Compostella, and R. D'Elia, "Cardiovascular autonomic neuropathy in HIV-positive African patients," Minerva Cardioangiologica, vol. 56, no. 4, pp. 417-428, 2008.

[26] D. Correia, L. A. P. Rodrigues De Resende, R. J. Molina et al., "Power spectral analysis of heart rate variability in HIV-infected and AIDS patients," PACE-Pacing and Clinical Electrophysiology, vol. 29, no. 1, pp. 53-58, 2006.

[27] WHO Expert Committee, "Physical status: the use and interpretation of anthropometry," Technical Report Serie 1995.

[28] J. C. Seidell, H. S. Kahn, D. F. Williamson, L. Lissner, and R. Valdez, "Report from a centers for disease control and prevention workshop on use of adult anthropometry for public health and primary health care," American Journal of Clinical Nutrition, vol. 73, no. 1, pp. 123-126, 2001.

[29] M. Malik, A. J. Camm, J. T. Bigger Jr. et al., "Heart rate variability. Standards of measurement, physiological interpretation, and clinical use," European Heart Journal, vol. 17, no. 3, pp. 354-381, 1996.

[30] A. Boardman, F. S. Schlinwein, A. P. Rocha, and A. Leite, "A study on the optimum order of autoregressive models for heart rate variability. Matlab-customized software developed in our laboratory was used in the temporal and spectral analysis," Physiological Measurement, vol. 23, pp. 325-326, 2002.

[31] "Seventh Report of the Joint National Committee on Prevention, Detection, Evaluation, and Treatment of High Blood Pressure (JNC 7)," http://www.nhlbi.nih.gov/guidelines /hypertension/.

[32] American Diabetes Association, "Standards of medical care in diabetes_2007," Diabetes Care, vol. 30, supplement 1, pp. S4S41, 2007.

[33] National Cholesterol Education Program (NCEP) Expert Panel on Detection, Evaluation, and Treatment of High Blood Pressure in Adults (Adult Treatment Panel III), "Third report of the National Cholesterol Education Program (NCEP) Expert Panel on Detection, Evaluation, and Treatment of High Blood Cholesterol (Adult Treatment Panel III) final report," Circulation, vol. 106, pp. 3143-3421, 2002.

[34] R. E. Maser and M. J. Lenhard, "REVIEW: cardiovascular autonomic neuropathy due to diabetes mellitus: clinical manifestations, consequences, and treatment," Journal of Clinical Endocrinology and Metabolism, vol. 90, no. 10, pp. 5896-5903, 2005.

[35] M. D. Rollins, J. G. Jenkins, D. J. Carson, B. G. McClure, R. H. Mitchell, and S. Z. Imam, "Power spectral analysis of the electrocardiogram in diabetic children," Diabetologia, vol. 35, no. 5, pp. 452-455, 1992.

[36] K. Javorka, J. Javorková, M. Petrášková, I. Tonhajzerová, J. Buchanec, and O. Chromá, "Heart rate variability and cardiovascular tests in young patients with diabetes mellitus type 1," Journal of Pediatric Endocrinology and Metabolism, vol. 12, no. 3, pp. 423-431, 1999.

[37] M. Javorka, I. Žila, T. Balhárek, and K. Javorka, "Heart rate recovery after exercise: relations to heart rate variability and coplexity," Brazilian Journal of Medical and Biological Research, vol. 35, no. 8, pp. 991-1000, 2002.

[38] J. Gerritsen, J. M. Dekker, B. J. TenVoorde et al., "Glucose tolerance and other determinants of cardiovascular autonomic function: the Hoorn Study," Diabetologia, vol. 43, no. 5, pp. 561-570, 2000.

[39] D. Liao, J. Cai, F. L. Brancati et al., "Association of vagal tone with serum insulin, glucose, and diabetes mellitus - the ARIC study," Diabetes Research and Clinical Practice, vol. 30, no. 3, pp. 211-221, 1995.

[40] J. P. Singh, M. G. Larson, C. J. O’Donnell et al., “Association of hyperglycemia with reduced heart rate variability (The Framingham Heart Study)," American Journal of Cardiology, vol. 86, no. 3, pp. 309-312, 2000.

[41] R. Lampert, J. D. Bremner, S. Su et al., "Decreased heart rate variability is associated with higher levels of inflammation in middle-aged men," American Heart Journal, vol. 156, no. 4, pp. 759.e1-759.e7, 2008. 


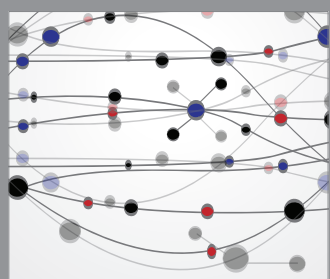

The Scientific World Journal
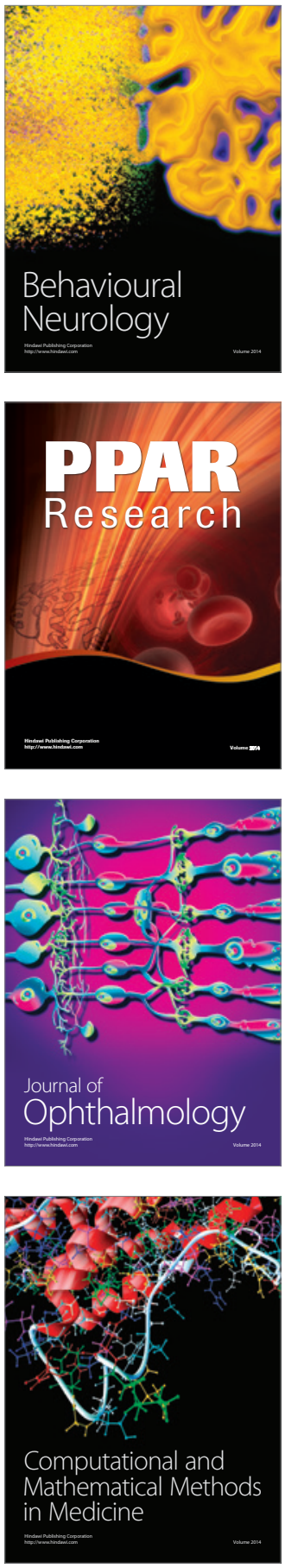

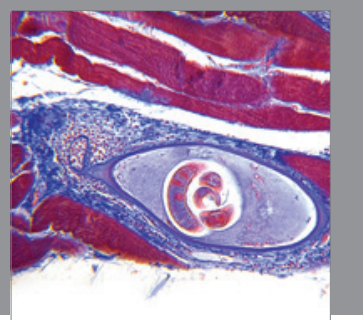

Gastroenterology

Research and Practice
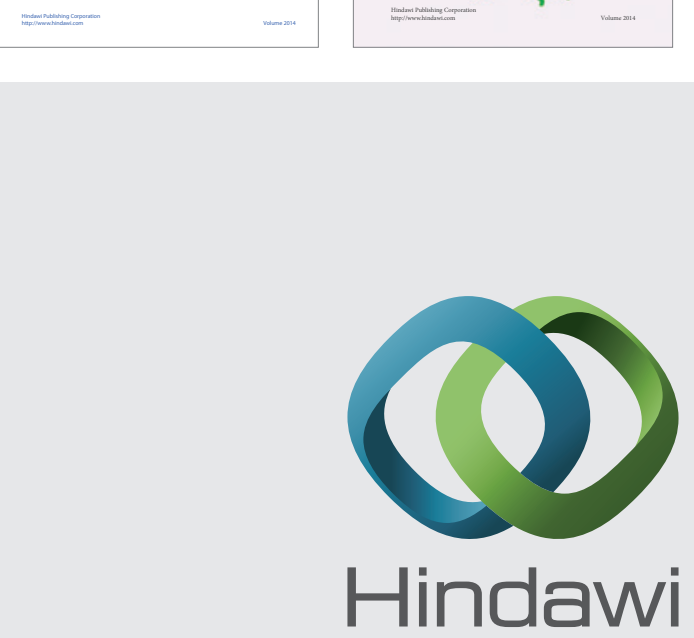

Submit your manuscripts at

http://www.hindawi.com
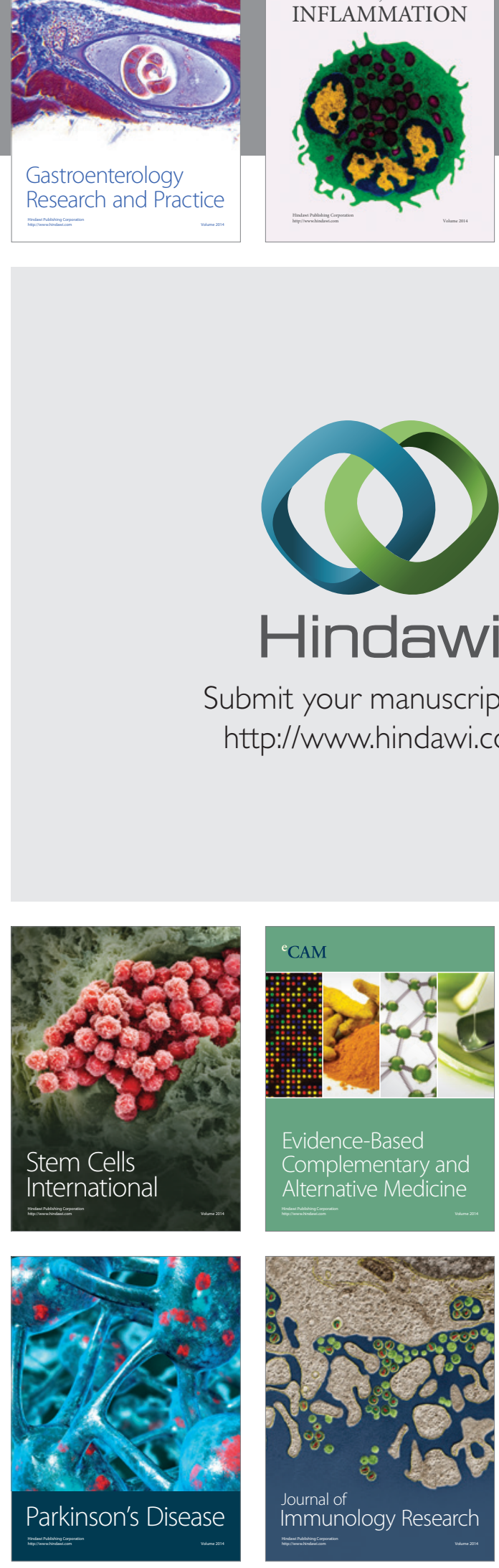

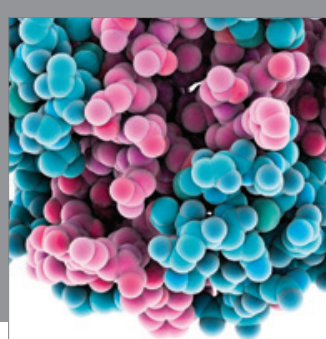

Diabetes Research
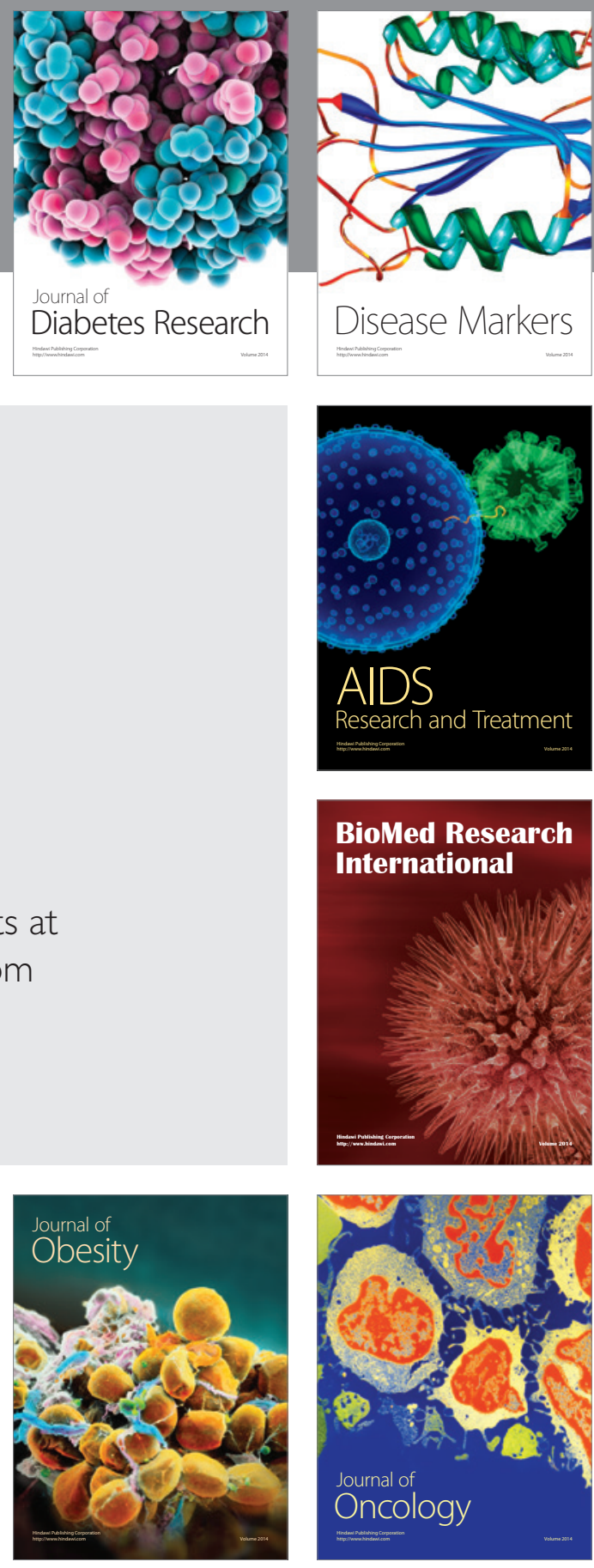

Disease Markers

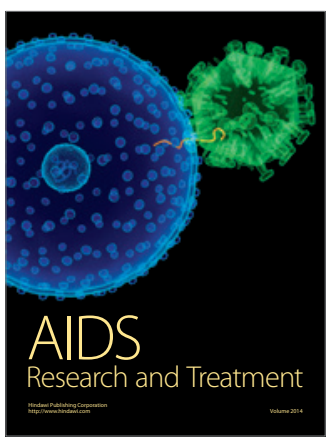

BioMed Research

International
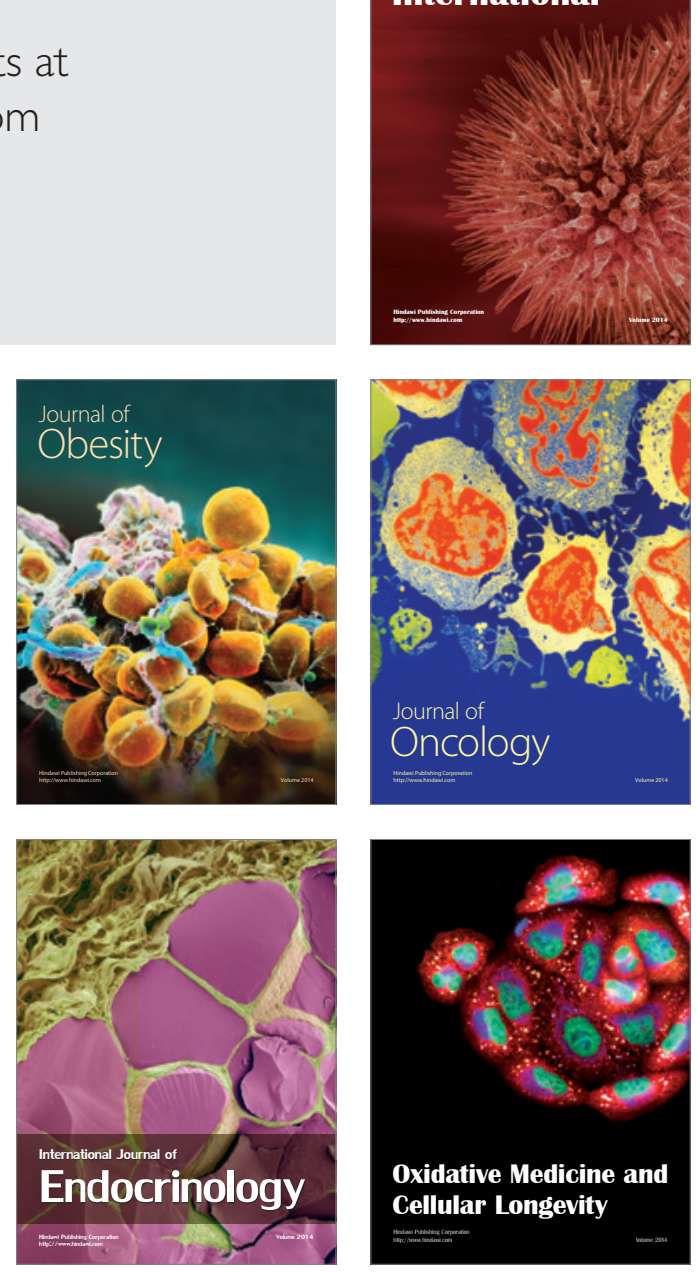